\title{
ANALISA PENERAPAN LEAN WAREHOUSE DAN 5S+SAFETY DI GUDANG PT. NICHIRIN INDONESIA
}

\author{
Kusnadi $^{1}$, Asep Erik Nugraha ${ }^{2}$, H. Wahyudin ${ }^{3 *}$ \\ ${ }^{1,2,3}$ Program Studi Teknik Industri Fakultas Teknik Universitas Singaperbangsa Karawang \\ Jl. H.S. Ronggowaluyo, Teluk Jambe Karawang, Jawa Barat 41361 \\ tikuk.kusnadi@yahoo.com ${ }^{2}$ nugraha_ae@yahoo.co.id ${ }^{3}$ wahyudin@ft.unsika.ac.id
}

Dikirimkan: 02, 2018. Diterima: 05, 2018. Dipublikasikan: 05, 2018.

\begin{abstract}
The company has a problem in warehouse layout arrangement so it will cause some kind of waste in the warehouse such as long searching time when searching spare parts in warehouse, transportation time when bringing material to warehouse or from warehouse to outside warehouse and transportation time at time of arrangement of material to storage shelf. Besides the problem that is noticed is the handling of discontinue material and the completeness of safety for warehouse operators. The purpose of this study can know the whole activity and the kinds of waste that occurred, so that can be done to the improvement of activity in the storage. The method used in measurement using fishbone diagram, and use Tools $5 S+$ Safety. Based on the calculation that utility use of warehouse space owned raw material PT. Nichirin Indonesia is close to 70\%. Layout raw material for now 77\% of raw material is already used for material storage. After the layout improvements, the utility of raw material usage is reduced to $37.11 \%$. various wastes that occur among others, Waiting time on goods delivery activities from suppliers, Transportation time on activities to bring goods from outside to the receiving area, Waiting time because the material must wait arranged by the admin / operator who works, Transportation time at the time of setting goods to shelf and Searching time on activities to find material for production needs. To reduce the waste that occurred among others, Add material handling in the form of trolley goods and ladder to shorten the transportation time, Make changes to warehouse layout and Provide labeling / coding on each area of the material rack
\end{abstract}

Keywords: Waste; Layout raw material; Fishbone diagram; Tools $5 S+$ Safety

\begin{abstract}
Abstrak- Perusahaan memiliki masalah dalam penataan layout gudang sehingga akan menimbulkan beberapa macam waste dalam gudang diantaranya searching time yang lama pada saat pencarian sparepart di warehouse, transportation time pada saat membawa material menuju gudang ataupun dari gudang ke luar gudang dan transportation time pada saat melakukan penataan material ke rak penyimpanan. Selain itu masalah yang kurang diperhatikan adalah penangan material yang sudah discontinue dan kelengkapan safety bagi operator gudang. Tujuan dari penelitian ini dapat diketahuinya keseluruhan aktivitas dan macam-macam pemborosan yang terjadi, sehingga bisa dilakukan perbaikan terhadap aktivitas di tempat penyimpanan. Metode yang digunakan dalam pengukuran menggunakan Diagram fishbone, serta mengunakan Tools $5 S+$ Safety. Berdasarkan perhitungan bahwa utilitas penggunaan ruang gudang yang dimiliki raw material PT. Nichirin Indonesia hampir mencapai 70\%. Layout raw material untuk saat ini $77 \%$ dari raw material sudah digunakan untuk melakukan penyimpanan material. Setelah dilakukan perbaikan layout, utilitas penggunaan raw material berkurang menjadi $37,11 \%$. macam-macam pemborosan yang terjadi diantaranya, Waiting time pada aktivitas pengiriman barang dari supplier, Transportation time pada kegiatan membawa barang dari luar menuju ke area receiving, Waiting time karena material harus menunggu ditata oleh admin/operator yang bekerja, Transportation time pada saat melakukan penataan barang ke rak dan Searching time pada kegiatan mencarikan material untuk kebutuhan produksi. Untuk mengurangi pemborosan yang terjadi diantaranya, Menambahkan material handling berupa trolley barang dan tangga untuk mempersingkat transportation time, Melakukan perubahan layout gudang dan Memberikan pelabelan/pengkodean pada setiap area rak material

Kata kunci : Waste ; Layout raw material ; Diagram fishbone ; Tools $5 S+$ Safety
\end{abstract}

\section{Pendahuluan}

Saat ini perkembangan dunia industri berlangsung dengan sangat cepat, salah satu perkembangannya yaitu dalam penggunaan bahan baku untuk mendukung berjalannya kelangsungan proses produksi. Bahan baku yang digunakan tersebut memerlukan tempat penyimpanan seperti 
gudang agar bahan baku tersebut tidak mengalami kerusakan karena cuaca. Penataan bahan baku tersebut juga sangat diperhatikan oleh perusahaan agar memberikan kenyamanan terhadap operator / penjaga, konsumen, ataupun supplier yang berhubungan langsung dengan gudang bahan baku. Sistem pergudangan yang kurang baik akan menimbulkan waste yang seharusnya masih dapat diminimalisir.

Perusahaan memiliki masalah dalam penataan layout gudang sehingga akan menimbulkan beberapa macam waste dalam gudang diantaranya searching time yang lama pada saat pencarian sparepart di warehouse, transportation time pada saat membawa material menuju gudang ataupun dari gudang ke luar gudang dan transportation time pada saat melakukan penataan material ke rak penyimpanan. Penataan layout waste juga terjadi pada saat menunggu barang yang datang dari supplier,ini terjadi karena layout area receiving yang kurang memadai. Supplier yang datang tidak tahu harus meletakkan barang yang dikirim karena tidak jelasnya area receiving. Selain itu masalah yang kurang diperhatikan adalah penangan material yang sudah discontinue dan kelengkapan safety bagi operator gudang.

Untuk itu diperlukan pendekatan lean warehouse dalam memperbaiki sistem pergudangan sparepart sehingga menciptakan proses kerja yang mengalir dengan lancar dan memberikan kenyamanan bagi pihak - pihak yang berhubungan langsung dengan gudang tersebut.

Permasalahan yang muncul yaitu bagaimana meningkatkan produktivitas perusahaan dengan mengidentifikasi waste di gudang dengan pendekatan lean warehouse yang ada pada proses dari awal barang masuk sampai barang sampai di gudang dan sistem penyimpanannya tahapannya mulai dari Value stream mapping, diagram fishbone, $5 S+$ Safety dan perbaikan layout.

Menurut (Jeffrey K. Liker, 2006) prinsip utama dari pendekatan lean adalah pengurangan atau peniadaan pemborosan (waste). Dalam upaya menghilangkan waste, maka sangatlah penting untuk mengetahui apakah waste itu dan dimana ia berada. Dalam buku The Toyota Way, terdapat 8 hal yang menyebabkan terjadinya waste diantaranya ; Over production, waktu menunggu, transportasi yang tidak perlu, proses secara berlebihan/keliru, persediaan berlebihan, gerakan yang tidak perlu, produk cacat, dan kreatifitas yang tidak dimanfaatkan. Diagram fishbone merupakan diagram yang digunakan untuk mengidentifikasi faktor penyebab problem/masalah, terdiri dari : material/bahan baku, mesin, manusia, lingkungan dan metode/cara.

Tujuannya yaitu untuk dapat diketahuinya keseluruhan aktivitas dan macam-macam pemborosan yang terjadi, sehingga bisa dilakukan perbaikan terhadap aktivitas di tempat penyimpanan.

\section{Metodologi Penelitian}

Berdasarkan latar belakang masalah dan tujuan yang akan dicapai dalam penelitian ini maka penulis melakukan pengumpulan data dan pengamatan. Gambar 1 merupakan bagan alur input dari supplier ke gudang, sedangkan gambar 2 merupakan bagan alur ouput (issue) dari gudang ke produksi.

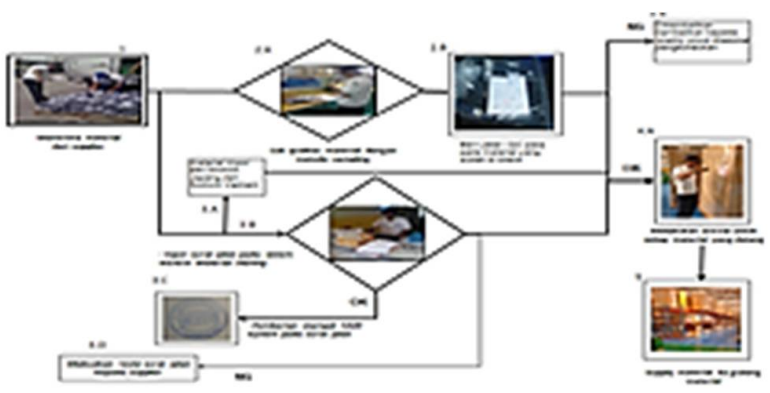

Gambar 1. Bagan alur input dari supplier ke gudang

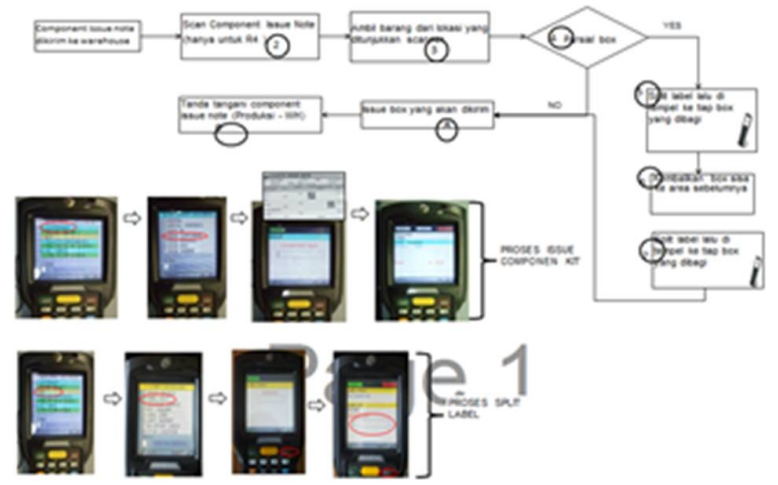

Gambar 2. Bagan alur output (issue) dari gudang ke produksi

Pada gambar 3 terlihat alur penempatan material (booked in) pada raw material, dan gambar 4 merupakan bagan alur stock opname pada raw material. 


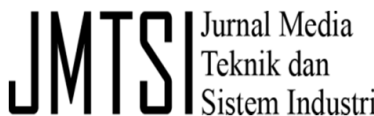

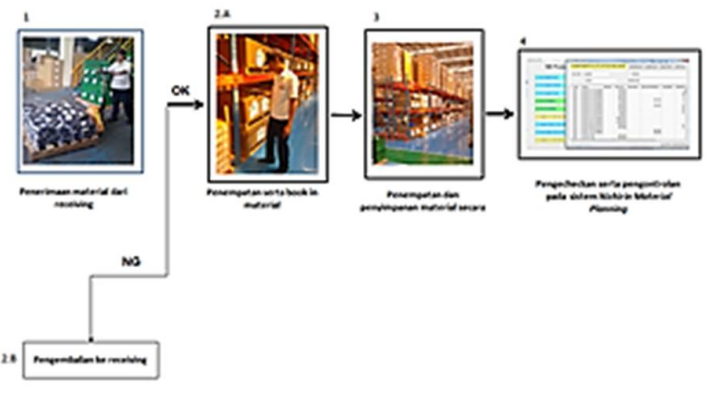

Gambar 3. Bagan alur penempatan material (booked in) pada raw material

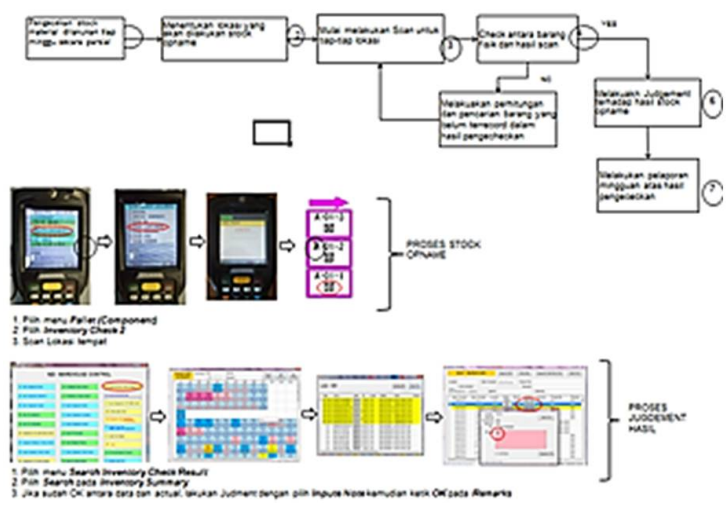

Gambar 4. Bagan alur stock opname pada raw material

Setelah permasalahan yang timbul di warehouse diketahui, maka akan bisa dilakukan perbaikan dan penambahan material handling dengan melakukan pengukuran dengan menggunakan Diagram fishbone, serta mengunakan Tools 5S+Safety.

\section{HASIL PENELITIAN}

Keadaan Warehouse PT.Nichirin Indonesia.Gudang Material atau biasa disebut dengan raw material PT. Nichirin Indonesia merupakan sebuah gudang yang khusus menyediakan dan menyimpan bahan baku dan kebutuhan-kebutuhanyang diperlukan untuk keperluan bahan baku PT. Nichirin Indonesia memilikiukuran $640 \mathrm{~m} 2$. Di dalam raw material PT. NID terdapat 6 rak yang digunakan untuk menyimpan keseluruhan material bahan baku. Diklasifikasikan menjadi 4 macam yaitu material $\mathrm{R} 2$, material R4, material hose fuel, danmaterial torque. Selain rak untuk menyimpan bahan baku juga terdapat meja kerja untuk meletakkan 1 unit komputer, 1 meja untuk meletakkan 2 printer dan telepon serta 1 rak dokumen untuk meletakkan segala arsip-arsip yang dibutuhkan oleh gudang.
Rak yang dimiliki oleh raw material rata - rata memiliki ketinggian 7 meter dengan rata - rata panjang rak 3 meter dengan 3 hingga 4 sekat atau ruang yang digunakan untuk memisahkan sparepart yang disimpan. Untuk penataan material awalnya ditata sesuai dengan klasifikasi part yang sudah ditentukan, akan tetapi karena keterbatasan tempat akhirnya peletakan / penataan sparepart dilakukan secara random (dimana ada tempat kosong,maka di tempat itu material diletakkan). Selain itu disekitar gudang juga terdapat baris-baris pallet yang digunakan untuk menyimpan material di luar rak.

Untuk proses pergudangan PT. NID sudah menggunakan system barcoding sesuai dengan standar Nichirin Group. System yang ada mencakup dari hal pembelian,penerimaan,raw material,finishedgoods, produksi,hinggaadelivery. Semua aktifitas yang ada di dalam perusahaan sudah saling berhubungan atas kepentingan satu sama lain antar departemen, sehingga mempermudah dalam penyampaian informasi. Pada Departemen Warehouse itusendiri system barcode yang digunakan sudah dapat diterapkan untuk beberapa proses seperti :

\section{A. Receiving}

Proses penerimaan material,baik material lokal ataupun dari impor. Bagian receiving melakukan penerimaan material dan pengecekan terhadap barang-barang yang diterima sesuai dengan dokumen pengiriman dari supplier.Receiving di PT. NID itu sendiri terdapat 2 jenis proses yang ada yaitu :

1. Proses penerimaan barang lokal:
a) Check barang dengan quantity yang ada,sesuai atau tidak dengan surat jalan
b) Administrasi surat jalan
c) Dibuatkan barcode

2. Proses penerimaan barang impor:
a) Scan arrival pada pallet contens
b) Buatkan pallet set dengan me-scan barang
c) Booked In pada lokasi

Permasalahan yang terdapat di raw material PT.NID digambarkan dengan value stream mapping. Dapat dikelompokkan menjadi 3 aktivitas seluruh kegiatan-kegiatan yang ada diraw material .Pada masing-masing aktivitas tersebutakan digambarkan melalui value stream mapping dan akan diketahui letak permasalahan dan waste apa saja yang terjadi. Ketiga aktivitas tersebut diantaranya aktivitas pengiriman barang dari supplier, aktivtas permohonan permintaan barang ke gudang, dan aktivitas pengiriman 
barang ke produksi. Berikut merupakan value stream mapping dari aktivitas pengiriman barang dari supplier:

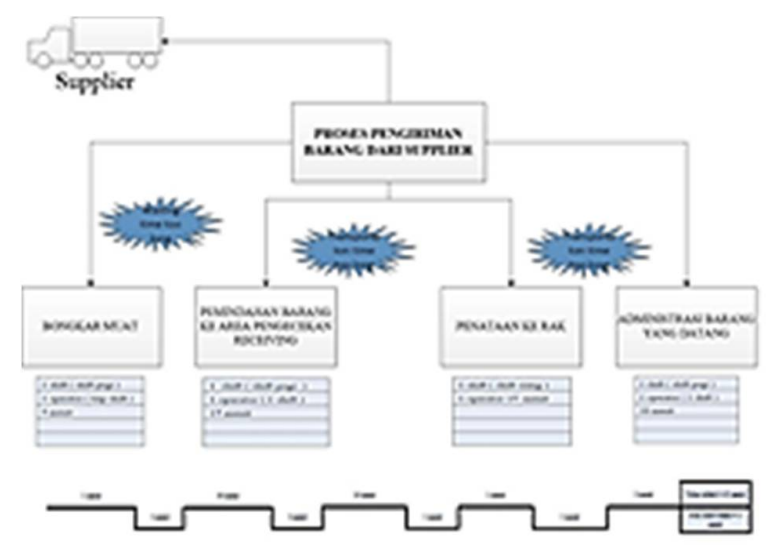

Gambar 5. Value Stream Mapping Pengiriman Barang dari Supplier

TABEL I

AKTIVITAS PENGIRIMAN BARANG DARI SUPPLIER

\begin{tabular}{|c|c|c|c|}
\hline No & Keglatan & Waktu & Keterangan \\
\hline 1. & Leadrime mennazgu barang dunag & 1 mingra & $\begin{array}{l}\text { Non valus sdding } \\
\text { but necessary }\end{array}$ \\
\hline 2 & Boagles mat & 5 motat & $\begin{array}{c}\text { Non valos adding } \\
\text { but nescrary }\end{array}$ \\
\hline 3. & Lesdtime & 1 monit & Nen valos adding \\
\hline 4. & $\begin{array}{l}\text { pemindala barang ke gudeag da } \\
\text { pengocekna }\end{array}$ & 20 menit & $\begin{array}{c}\text { Non vasese ading } \\
\text { but nocssary }\end{array}$ \\
\hline 5. & Lesdime & 4 jactin & Non vasos adding \\
\hline 6. & penatasa ke rak & 20 metis & Valos adfiaz \\
\hline 7. & Leadtime & 7 jam & Non vales adding \\
\hline$\$$. & Peodetan burmet yang datans & 10 ments & Valos adting \\
\hline
\end{tabular}

Sumber : Pengumpulan Data 2015

Berikut merupakan value stream mapping dari aktivitas Proses Issuing Components :

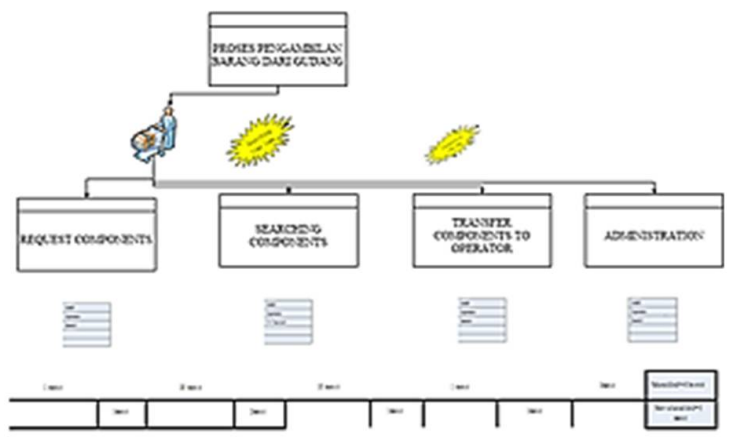

Gambar 6. Value Stream Mapping Proses Issuing Components

TABEL II

AKTIVITAS PROSES ISSUING COMPONENTS

\begin{tabular}{|c|c|c|c|}
\hline So & Kegiatan & Waktu & Keterangan \\
\hline 1 & $\begin{array}{c}\text { permoboenn burang be } \\
\text { eperator }\end{array}$ & 1 menit & $\begin{array}{c}\text { Non value adding ber } \\
\text { necessary }\end{array}$ \\
\hline 2 & Leadtime & 1 menit & Nea valuesdding \\
\hline 3 & Pescarian material & 30 menit & $\begin{array}{c}\text { Non value adding be } \\
\text { necessary }\end{array}$ \\
\hline 4 & Leadtime & 2 meait & not valucadting \\
\hline $\mathbf{s}$ & $\begin{array}{l}\text { Perrindahan material ke } \\
\text { area kanban }\end{array}$ & 10 menit & $\begin{array}{c}\text { Non value adsing be } \\
\text { necendary }\end{array}$ \\
\hline 6 & Leadtime & 1 menit & Don valoessting \\
\hline 7 & Pencrimatn material & 1 menit & $\begin{array}{c}\text { Non value asking be } \\
\text { necessary }\end{array}$ \\
\hline 8 & Leadtime & 1 menit & noa valoessaing \\
\hline 9 & Adrinistrasi & 3 menat & vaveadsing \\
\hline
\end{tabular}

Pada gambar 5. terdapat value stream mapping untuk aktivitas pengiriman barang dari supplier. Setelah barang diantarkan oleh mobil angkut supplier, barang tersebut yang merupakan material dibongkar muat dengan waktu bongkar muat adalah 5 menit. Setelah dibongkar muat kemudian material dipindahkan ke dalam gudang. Pada kegiatan ini memiliki waktu transportasi yang lama yaitu 20 menit. Hal ini dikarenakan pada saat memindahkan barang ke gudang tidak menggunakan alat bantu dan karena layout yang kurang mendukung sehingga menyebabkan pemindahan barang menjadi lama. Kemudian untuk menata material yang datang di shift pagi harus menunggu terlebih dahulu pekerja yang bekerja dishift 2 terkendala dengan tenaga dan pekerjaan yang banyak sehingga penataan material tersebut mengalami penundaan selama 4 jam untuk ditata ke rak penyimpanan. Setelah itu pada waktu proses penataan ke rak juga mengalami transportation time yang lama terkendala dengan layout yang kurang teratur sehingga tidak leluasa dalam memindahkan dan meletakkan barang ke rak. Setelah barang ditata kemudian dilakukan pendataan material. Pendataan biasa dilakukan pada saat jam kerja shift 1 selesai dengan waktu 10 menit. Pada kegiatan - kegiatan terdapat banyak kegiatan non value adding yang harus direduksi untuk memperlancar aktivitas pengiriman sparepart sampai sparepart ditata pada rak raw material.

Pada gambar 6 terdapat value stream mapping untuk aktivitas permohonan pengambilan barang dari raw material. Pada gambar tersebut terdapat 5 kegiatan. Operator melakukan permohonan permintaan material kepada admin / operator raw materil. Kegiatan itu berlangsung selama 1 menit. Setelah operator 


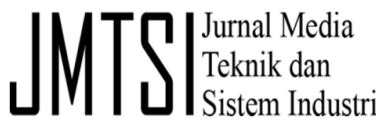

memberitahu material apa saja yang dibutuhkan, kemudian admin / operator mulai melakukan pencarian sparepart. Terdapat searching time yang lama pada kegiatan ini yaitu 30 menit dikarenakan terkadang ada material yang lupa dalam peletakan dan area penyimpanan material yang ada raw material. Selain itu karena peletakan sparepart yang tidak teratur. Setelah dilakukan pencarian material,material diserahkan kepada opertor yang membutuhkan. Kegiatan ini juga terkendala dalam masalah transportation time yang lama yaitu 10 menit. Karena letak rak yang jaraknya terlalu dekat dan banyak barang - barang yang diletakkan dilantai sehingga menyebabkan operator kesusahan dan tidak leluasa dalam membawa sparepart untuk diserahkan kepada operator. Kemudian sparepart diterima oleh operator dan kemudian dilakukan pendataan oleh admin / operator raw material.

Diagram fishbone merupakan sebuah diagram yang menggambarkan sebuah dampak atau akibat dari sebuah permasalahan, dengan berbagai penyebabnya. Diagram fishbone sering disebut dengan cause effects diagram. 4 parameter yang digunakan untuk menilai masalah yang ada dilihat dari sisi man, machine, methods, material dan enviromental. Berikut diagram fishbone dari aktivitas - aktivitas yang ada di gudang raw material PT.Nichirin Indonesia

Gambar 7 merupakan diagram fishbone dari aktivitas pengiriman barang dari supplier. Berdasarkan diagram fishbone terseut, dapat diketahui masalah yang terjadi pada aktivitas pengiriman barang dari supplier adalah transportation dan waiting time yang terlalu lam yang disebabkan oleh beberapa hal yaitu:

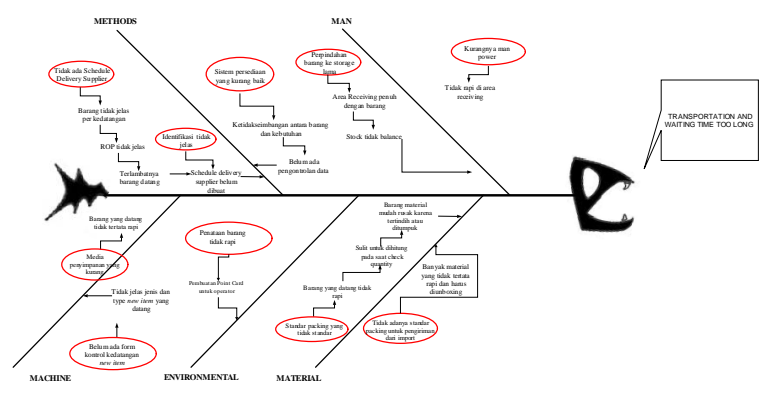

Gambar 7. Fishbone Aktivitas Pengiriman Barang dari Supplier
A. Man / manusia
Pada aktivitas pengiriman barang dari supplier, tenaga pria yang bekerja pada satu shift

di receiving $\mathrm{PT}$ Nichirin Indonesia masih sangat kurang. Karena apabila barang dari supplier datang pada saat jam kerja shift 1, penataan material tersebut harus menunggu terlebih dahulu menyeleseaikan supplai barang sehingga belum tentu dalam satu shift dapat menyelesaikan pekerjaannya. Sehingga terjadi waiting time pada penataan material. Selain itu, pekerja disini tidak hanya melayani pengambilan dan penerimaan barang, tetapi juga mencatat segala proses administrasi yang berlangsung didalam gudang raw material. Dengan jobdesk yang diberikan kepada pekerja tersebut tidak cukup adanya 1 pekerja dalam 1 shift. Setidaknya terdapat 2 pekerja dalam 1 shift yaitu 1 orang bagian pelayanan material dan 1 orang bagian yang mengerjakan bongkar dan menata material yang datang pada receiving. Pada raw material dan receiving $\mathrm{PT}$. Nichirin Indonesia, saat ini pekerja yang bekerja dishift 1 satu orang wanita dan 1 orang pria pada shift 1 dan pekerja dishift 2 juga memiliki 1 pekerja saja ( seorang pria).

\section{B. Machine / Mesin}

Pada aktivitas pengiriman barang dari supplier, material handling atau alat bantu bawa masih sangat kurang. Sehingga saat supplier datang tidak dapat tertata rapih untuk membawa barang yang dikirim.. Selain itu tidak adanya tangga untuk meletakkan material yang terletak di rak paling atas sehingga harus memanjat sisi sisi rak / kardus - kardus. Rak yang digunakan untuk menyimpan sparepart juga kurang sehingga perlu adanya penambahan rak.

\section{Methods / Metode}

Pada raw material dan receiving metode pelabelan/pengkodean pada material masih kurang diterapkan. Tidak semua material diberikan pelabelan/pengkodean. Terlebih untuk material spesial/khusus/new item yang digunakan untuk trial new item yang memiliki nama material dengan pelafalan yang susah untuk dimengerti dan jarang distock oleh raw material. Kurangnya pelabelan/pengkodean dapat menyebabkan searching time yang terlalu lama.

Penataan sparepart pada raw material juga awalnya sudah sesuai klasifikasi jenis material, tetapi karena keterbatasan tempat maka penempatan material di raw material saat ini sudah tidak mempertimbangkan jenis material tersebut.

Dalam pemesanan materialmasih sering mengalami tidak menentunya kedatangan material. Maka untuk mengatasi hal tersebut diterapkan sistem reorder point dalam 
pemesanan material agar dapat diketahui pada stok material masih berapa item raw material harus memesan material. Sehingga nantinya terdapat safety stock yang menutupi kekurangan stok pada saat sparepart belum datang. Dan diinformasikan juga schedule delivery supplier pada bagian receiving agar mengetahui kapan kedatangan barang tersebut

\section{Enviromental / Lingkungan}

Penataan sparepart yang kurang teratur menyebabkan transportation time dan waiting time yang lama. Karena penataan sparepart yang kurang teratur terseebut ruang gerak admin/operator pada saat mengambil atau mengantarkan barang ke gudang menjadi lambat.

\section{E. Material / Bahan}

Standar packing yang tidak teratur menyebabkan transportation time dan waiting time lama. Karena operator harus menata ulang kembali barang per item dan meyusunnya. Selain itu juga barang yang datang sulit untuk disusun karena volume dan berat dari barangnya itu sendiri.

Dapat terlihat dari gambar 8, terdapat banyak tumpukan - tumpukan kardus berisi material yang diletakkan tidak beraturan di lantai gudang raw material. Utilitas / penggunaan ruangan dari kardus - kardus yang ada di lantai tersebut sebesar $=(2,014 \mathrm{~m} 2+0,9472 \mathrm{~m} 2+$ $0,456 \mathrm{~m} 2+0,5216 \mathrm{~m} 2+0,444 \mathrm{~m} 2+0,3276 \mathrm{~m} 2$ $+1,1 \mathrm{~m} 2+0,888 \mathrm{~m} 2+1,036 \mathrm{~m} 2+4,2 \mathrm{~m} 2+6$ $\mathrm{m} 2+2,2776 \mathrm{~m} 2)=20,21$

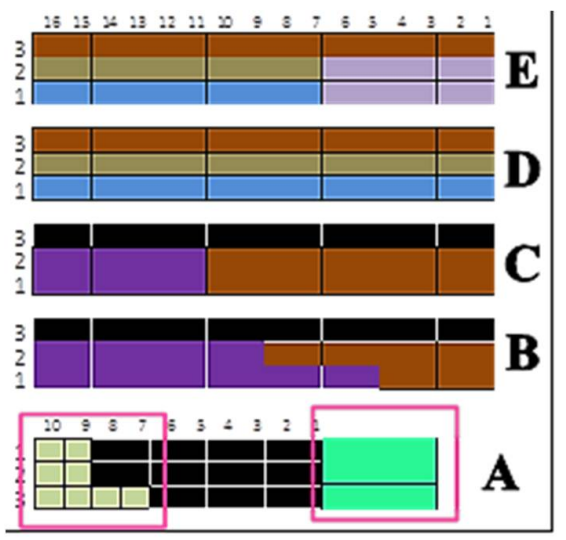

Gambar 8. Gambar Gudang PT.Nichirin Indonesia

Keterangan gambar:

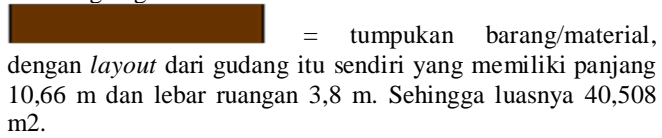

Di dalam raw material juga terdapat beberapa rak penyimpanan. Rak penyimpanan material yang ada di dalam raw material sejumlah 7 buah rak penyimpanan yang disusun secara horizontal (gambar. 10). Rak yang disusun secara horizontal rata-rata memiliki ukuran panjang=300 $\mathrm{cm}$ dan lebar $=50 \mathrm{~cm}$.

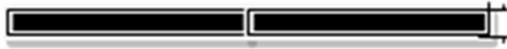

Gambar 9. Rak Penyimpanan Material ( arah horizontal)

$$
\begin{array}{ll}
\text { Luasrak horizontal } & =\mathrm{p} \times 1 \\
& =3 \mathrm{~m} \times 0,5 \mathrm{~m} \\
& =1,5 \text { meter } 2
\end{array}
$$

Luas rak yang disusun secara horizontal sebesar 1,5 meter2 dengan penyusunan rak berderet 7 rak kebelakang ruangan raw material. Jarak antar rak satu dengan yang lain yaitu sebesar $74 \mathrm{~cm}$ sehingga utilitas / penggunaan ruangan pada rak yang disusun secara horizontal sebesar $=1,5$ meter $\times 7$ rak $=10,5$ meter 2 .

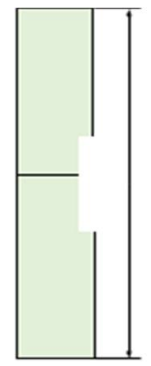

Gambar 10. Lemari Penyimpanan Material ( arah vertikal)

$$
\begin{aligned}
\text { Luas rak vertikal } & =\mathrm{p} \times 1 \\
& =3 \mathrm{~m} \times 0,5 \mathrm{~m} \\
& =1,5 \text { meter } 2
\end{aligned}
$$

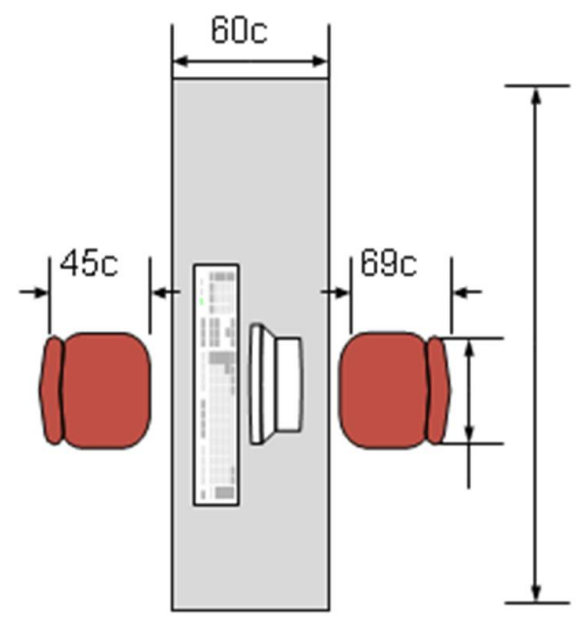


Gambar 11. Meja Kerja Admin

Luas meja kerja admin $=\mathrm{p} \times 1$

$=1,5 \mathrm{~m} \times 1,2 \mathrm{~m}$

$=1.8$ meter

Luas tempat duduk admin $=\mathrm{px} 1$

$$
=0,84 \mathrm{~m} \times 0,45 \mathrm{~m}
$$$$
=0,378 \text { meter } 2
$$

Luas tempat duduk supplier $=\mathrm{p} \mathrm{x} 1$

$$
\begin{aligned}
& =0,77 \mathrm{~m} \mathrm{x} 0,69 \mathrm{~m} \\
& =0,53 \text { meter } 2
\end{aligned}
$$

Luas meja kerja admin yang terletak tepat di depan pintu masuk gudang sebesar 0,72 meter2. Kemudian untuk luas tempat duduknya sebesar $=(0,378$ meter $2+0,53$ meter 2$)=0,908$ meter2, sehingga utilitas / penggunaan ruangan pada meja dan kursi sebesar $=0,72$ meter $2+$ 0,908 meter $2=1,628$ meter

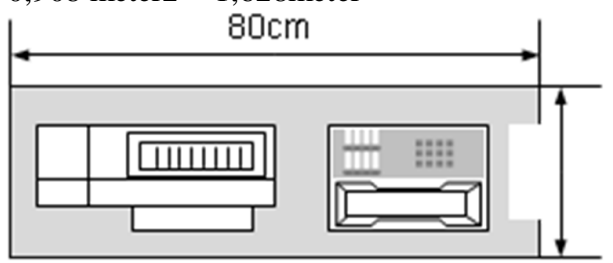

Gambar 12. Meja Printer dan Telepon

$$
\begin{aligned}
\text { Luas meja printer } & =\mathrm{p} \times 1 \\
& =0,8 \mathrm{~m} \times 0,35 \mathrm{~m} \\
& =0,28 \text { meter } 2
\end{aligned}
$$

Luas meja printer yang terletak disamping meja kerja admin sebesar 0,28 meter2. Sehingga utilitas / penggunaan ruangan pada meja printer sebesar $=0,28$ meter 2

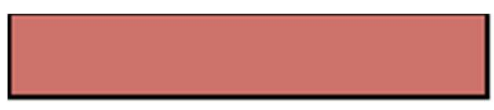

Gambar 13. Rak Dokumen

$$
\begin{aligned}
\text { Luas rak buku } & =\mathrm{p} \mathrm{xl} \\
& =2 \mathrm{~m} \times 0.5 \mathrm{~m} \\
& =1 \text { meter } 2
\end{aligned}
$$

Luas rak dokumen yang terletak tepat diatas meja printer sebesar 1 meter2.Rak dokumen pada gudang tidak berpengaruh dalam penghitungan utilitas penggunaan ruangan.

Berdasarkan kondisi penempatan rak, meja kerja dan barang - barang yang terdapat disekitar lantai gudang dilakukan perhitungan untuk mengetahui persentase utilitas ruang gudang yang ada sekarang. Utilitas ruang ini didapatkan melalui perbandingan antara jumlah area luas rak yang digunakan untuk meletakkan barang.

Berikut adalah perhitungan utilitas ruang gudang saat ini.

Luas area keseluruhan $\quad=540 \mathrm{~m}^{2}$

Luas area yang digunakan $=($ luas keseluruhan area rak horizontal + luas rak vertikal + luas meja kantor dan printer + luas material - material yang diletakkan di lantai)

$=7,5 \mathrm{~m} 2+1,5 \mathrm{~m}^{2}+1,908 \mathrm{~m}^{2}+20,212 \mathrm{~m}^{2}$

$=30,84 \mathrm{~m}^{2}$

Berdasarkan perhitungan tersebut dapat ditarik kesimpulan bahwa utilitas penggunaan ruang gudang yang dimiliki raw material PT. Nichirin Indonesia hampir mmencapai $70 \% .70 \%$ sebagian besar terdiri dari tumpukan - tumpukan material didalam kardus dimana dapat dilakukan racking system untuk mengatasi hal tersebut. Hampir keseluruhan dari area raw material sudah digunakan untuk menyimpan material. Sehingga harus dilakukan perubahan layout ulang dan menerapkan racking system pada gudang untuk mengurangi adanya waste yang terjadi pada gudang PT. Nichirin Indonesia.

\section{Tools ( 5 S + Safety)}

Salah satu tools yang digunakan untuk mengidentifikasi pemborosan dalam konsep lean manufacturing system adalah $5 \mathrm{~S}$. Dibawah ini adalah beberapa tahapan dalam penerapan konsep5S:

\section{A. Sort/Seiri(Ringkas)}

Sort merupakan langkah yang bertujuan untuk membuang yang tidak terpakai atau menyimpannya kembali. Pada permasalahan di gudang terdapat banyak kardus-kardus berisi material yang terletak tidak beraturan di lantai gudang. Selain kardus-kardus berisi material juga terdapat kardus-kardus kosong dan kardus-kardus yang sudah tidak layak untuk menyimpan. Hal ini menyebabkan ruang gerak operator/admin yang mengambilkan material menjadi tidak leluasa dan pergeseran material dari satu tempat ke tempat lain menjadi lambat.

\section{Rekomendasi:}

Sebaiknya material-material didalam kardus yang tidak rawan pecah/hancur dikeluarkan dari kardus ( contoh : protector, hose, dll ) kemudian ditata di rak penyimpanan. Untuk materialmaterial yang rawan pecah ( contoh : fitting) tetap dimasukkan di dalam kardus tetapi ditutup dengan rapat dan diletakkan di rak penyimpanan. 
Untuk kardus-kardus kosong sebaiknya dibuang, dan untuk kardus-kardus yang sudah tidak layak pakai lebih baik dibuang dan digantikan oleh kardus yang baru.Dengan penataan kardus berisi material tersebut di dalam rak penyimpanan, maka raw materaial tidak terihat begitu penuh dan operator / admin memiliki ruang gerak bebas.

\section{B. Straighten/Seiton(Rapi)}

Straighten merupakan langkah yang bertujuan agar barang diatur sedemikian rupa sehingga rapi dan mudah dicari. Dalam permasalahan yang ada di raw material terdapat material yang tidak teratur dalam penataannya. Kadang untuk material yang memiliki ukuran dijadikan satu tempat sehingga jika dilakukan pencarian material membutuhkan waktu yang lama. Terkadang terdapat material yang peletakannya tidak setempat dikarenakan melihat faktor seringnya dipakai material tersebut. Kemudian dalam penataan material, awalnya raw material diklasifikasikan menurut jenis material tetapi karena keterbatasan tempat peletakkan material saat ini menjadi tidak sesuai jenis materialnya.

Rekomendasi:

Sebaiknya proses penataan material di raw material tetap ditata menurut klasifikasi jenis materialnya ( misal : material R2,material $\mathrm{R} 4$,material hose fuel,dan material torque). Setelah itu, sebaiknya langsung di bookedn sesuai dengan tempatnya material agar mempermudah pencarian dan tidak perlu mencari material di seluruh area raw material sehingga tidak menyebabkan material berantakan.

\section{Shine/Seiso(Resik)}

Shine adalah pembersihan secara berkala. Pada raw material belum dikategorikan dalam keadaan bersih. Karena material yang datang dari supplier tidak langsung ditata di rak penyimpanan namun dibiarkan terlebih dahulu diletakkan di sekitar area receiving sehingga kadang material tersebut memenuhi ruangan dan menyebabkan ruang gerak admin/operator/supplier menjadi kurang bebas dan menyebabkan transportation time menjadi lama.

Rekomendasi:

Straighten berarti setelah selesai dilakukan proses incoming ataupun outgoing material, sebaiknya material langsung ditata dengan rapi di rak penyimpanan material. Sehingga tidak memenuhi area receiving.

\section{Standardize/Seiketsu(Rawat)}

Standardize merupakan tahapan kerja dimana perusahaan harus menciptakan atau membuat standar kerja. Apabila mempunyai standar tertentu dalam melakukan pekerjaan tentu hasilnya akan lebih baik dan apabila terdapat kesalahan akan mudah dalam penilaiannya karena ada standar yang menjadi acuan dalam penilaian tersebut. Pada gudang PT.Nichirin Indonesia proses pemesanan materialnya masih menggunakan cara manual. Belum menerapkan system ROP dan safety stock. Menerapkan sistem ROP dan safety stock dalam pemesanan material kembali agar tidak terjadi kekurangan stock pada saat material dari supplier datang.

\section{E. Sustain/Shitsuke(Rajin)}

Berarti kemampuan untuk melakukan sesuatu dengan cara yang benar sebagai suatu kebiasaan. Menjaga tempat kerja agar selalu stabil dan bersih merupakan proses yang terus menerus dari peningkatan berkesinambungan. Hal ini tergantung dengan aman. Sifat pekerja yang bekerja di gudang. Pekerja di gudang seharusnya membiasakan diri untuk menjaga kebersihan dan kerapian lingkungan kerjanya. Apabila pekerja sudah menerapkan selalu menjaga kebersihan di lingkungan kerjanya maka pekerja akan terbiasa dengan penerapan $5 \mathrm{~S}+$ safety.

\section{Safety}

Pekerjaan di gudang tidak hanya mencatat administrasi keluar masuknya material tetapi juga melayani pengambilan material untuk para operator produksi dan penyaluran material dari supplier. Material yang diangkut tidak hanya yang berukuran kecil, tetapi material yang berukuran besar dan berat juga diangkut seperti hose,fitting, rubber bush, dan conncto dll.Jika hal kecil dilakukan secara terus menerus akan berakibat fatal, misalnya saja pekerja dalam melakukan kegiatan penyaluran barang dari suplier ke gudang tidak menggunakan alat material handling, seperti troly. Ini mengakibatkan pekerja harus membawa kardus berat $20 \mathrm{~kg}$ untuk 1 kardus secara manual. Jika dibiarkan terus menerus akan mengakibatkan sakit punggung atau pundak pada pekerjanya.

Setelah dianalisa dengan menggunakan tools $5 S+$ Safety maka diberikan usulan perbaikan yang tepat yang akan diberikan untuk memperbaiki warehouse management system dan mereduksi waste pada gudang material PT. Nichirin Indonesia yaitu dengan cara menambahkan material handling dan mengubah 
layout pada gudang karena sebagian besar waste terjadi pada transportation time dan searching time yang terlalu lama. Usulan perbaikan yang akan diberikan yaitu berupa penambahan material handling, perbaikan layout dengan menggunakan kebijakan Class Based Storage Policy atau dapat disebut dengan klasifikasi ABC serta menerapkan racking system pada gudang, dan usulan perbaikan terakhir yaitu menekankan pada pekerja terhadap SOP yang berlaku disetiap aktifitas yang dilakukan.

Untuk mengurangi cedera / kecelakaan kerja pada tenaga kerja yang setiap harinya melakukan pengangkutan barang maka dibutuhkan alat bantu berupa trolly dan tangga untuk meringankan beban pekerja dan meminimalkan transportation time.

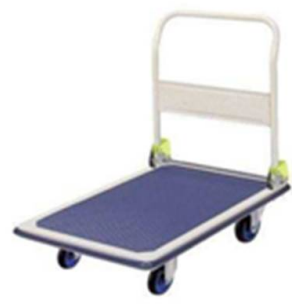

Gambar 14. Trolley

Nama trolley : Trolley lipat Prestar Jepang NF 301

Negara asal : Jepang

Kapasitas : $: 300 \mathrm{~kg}$

Dimensi : $920 \mathrm{~mm} \times 610 \mathrm{~mm}$

Roda : 5 inch

Pemilihan jenis trolley diatas berdasarkan barang yang diangkut biasanya mencapai $30 \mathrm{~kg}$ per barangnya dan sekali angkut biasanya mencapai $180 \mathrm{~kg}$. Dengan adanya trolley sebagai alat bantu kerja maka transportation time dalam memindahkan barang dapat berkurang. Selain itu dapat mengurangi segala bentuk keelakaan kerja akibat sering mengangkut barang - barang berat tanpa menggunakan alat bantukerja.

Pemilihan jenis tangga diatas karena melihat faktor keamanan.Pada tangga tersebut terdapat penyangga agar tangga terkunci.Selain itu tangga yang dipilih yaitu memiliki tinggi $3 \mathrm{~kg}$ agar dapat mencapai rak penyimpanan yang tertinggi. Dengan adanya tangga yang digunakan sebagai alat bantu, maka admin/operator tidak akan kesusahan dalam mencapai barang yang letaknya paling atas dan dapat mengurangi segala bentuk kecelakaan kerja.

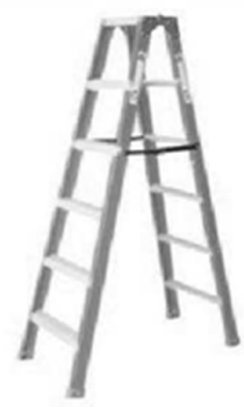

Gambar 15. Tangga

$\begin{array}{ll}\text { Nama tangga } & \text { : Tangga Caltec } \\ \text { Negara asal } & \text { :Indonesia } \\ \text { Kapasitas } & :- \\ \text { Dimensi : } 3 \mathrm{~m} & \end{array}$

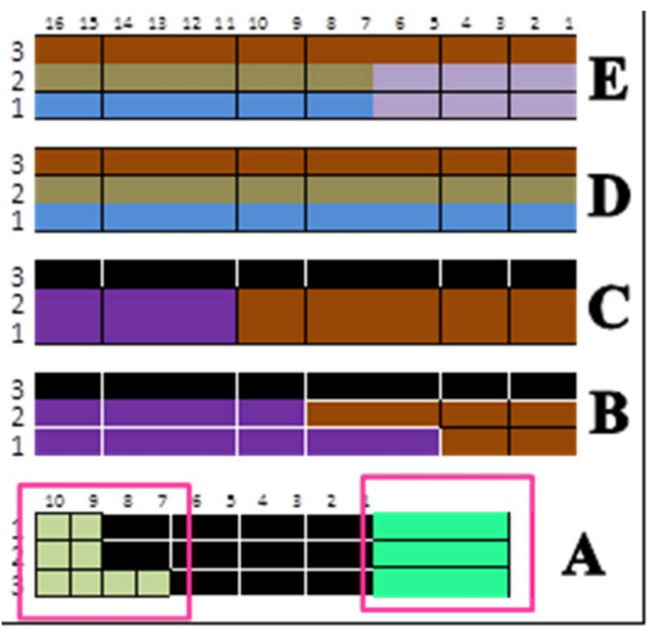

Gambar 16. Layout Gudang Material PT. Nichirin Indonesia

Layout raw material untuk saat ini $77 \%$ dari raw material sudah digunakan untuk melakukan penyimpanan material. Hal ini menyebabkan transportasi material dari dan ke gudang menjadi terhambat karena tidak leluasanya pekerja/admin dalam bergerak memindahkan barang. Selain itu penataan material yang kurang teratur dan kurangnya rak penyimpanan barang menyebabkan pencarian material menjadi sangat lama padahal tidak semua material di raw material belum dilakukan pelabelan pada material.

Dalam pembuatan layout usulan mempertimbangkan dari permintaan produksi pada raw material, untuk itu metode yang digunakan yaitu menggunakan kuesioner sebanyak 6 sampel dari karyawan dari PT. Nichirin Indonesia. Tabel III berikut menunjukan 
rekap data check sheet yang telah disalin ulang.

TABEL III

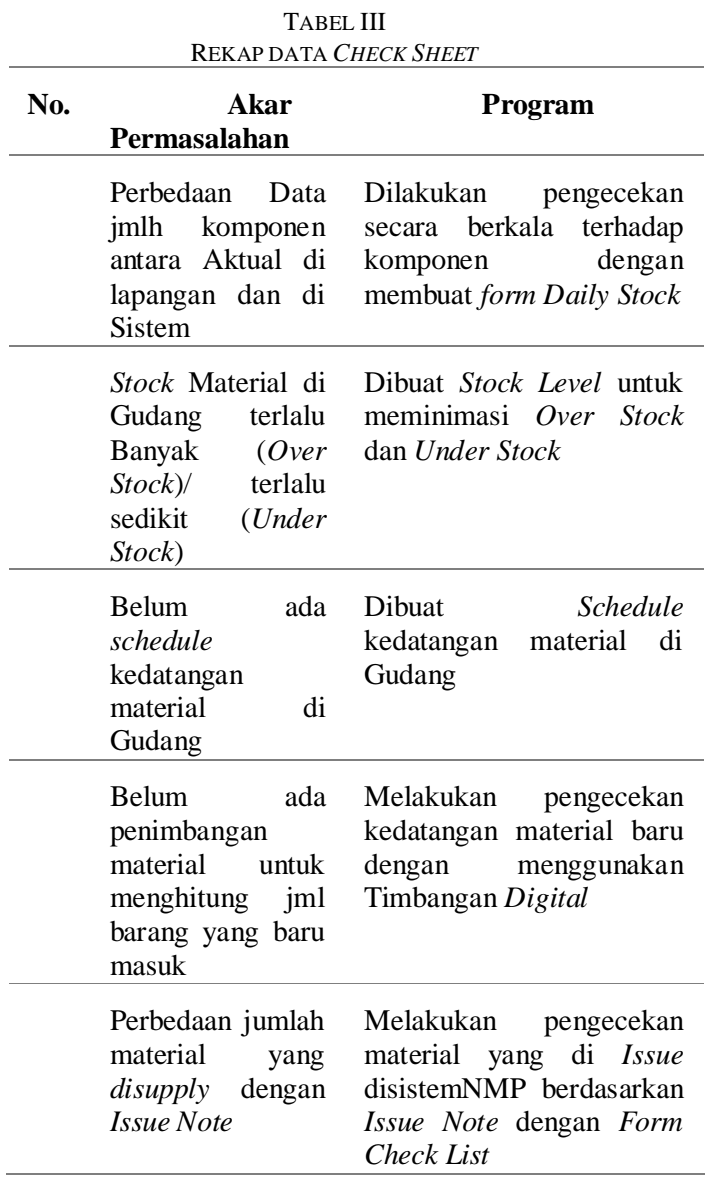

Berdasarkan hasil pendataan check sheet yang telah terlampir dapat diambil kesimpulan bahwa perancangan pola peletakkan material dilakukan dengan prinsip similarity dan tetap memperhatikan popularity dari masing-masing material. Selain itu pada gudang diterapkan racking system dengan memanfaatkan ketinggian untuk memperbanyak kapasitas dari gudang.

Pada prinsip ini, nantinya produk akan diklasifikan sesuai dengan metode klasifikasi $\mathrm{ABC}$, dimana kelas A menunjukkan produkproduk yang fast moving, kelas B untuk produk medium moving, dan kelas $\mathrm{C}$ untuk produk slow moving. Data total barang yang keluar periode desember-januari per material ditunjukkan telah diurutkan dari barang keluar yang terbanyak kemudian dihitung presentase komulatifnya dan diklasifikasikan dengan menggunakan metode $\mathrm{ABC}$.
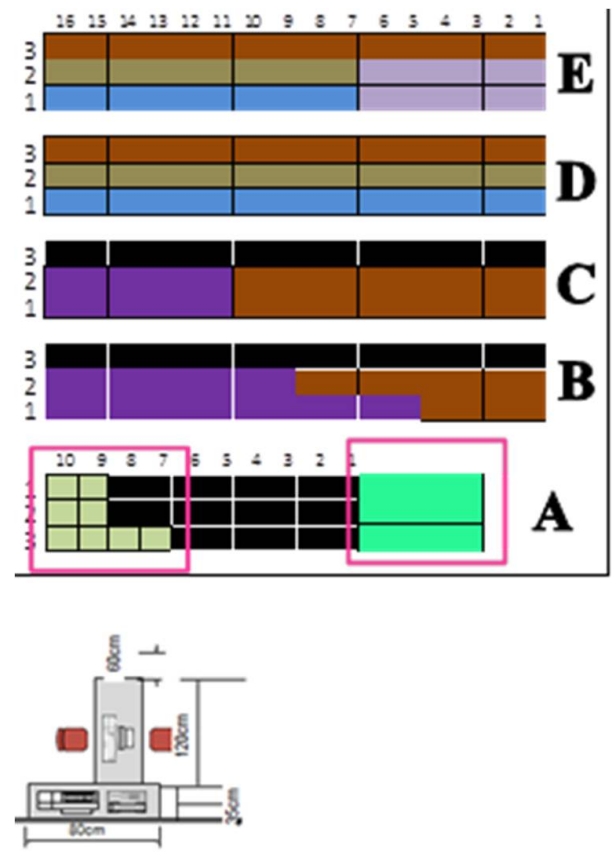

Gambar 17. Layout Raw Material ( ruangan lama)

Gambar 20. Merupakan layout gudang dengan ukuran lebar 60 meter dan panjang 10,66 meter sehingga luas yang dimiliki yaitu sebesar 639.6 meter2. Layout raw material sebelumnya, raw material memiliki 6 rak penyimpanan dimana 5 rak disusun secara horizontal ke belakang dan 2 rak penyimpanan menghadap vertikal. Kemudian setelah dilakukan penataan layout ulang. Terdapat penambahan rak penyimpanan sebanyak 4 rak penyimpanan dan 1 rak buku. Pada luar raw material terdapat 1 rak penyimpanan yang memiliki luas 15 meter2 yang direncanakan untuk penyimpanan sementara material impor. Penambahan rak tersebut menerapkan racking system sehingga materialmaterial didalam kardus yang diletakkan dilantai tidak memenuhi lantai dan dapat dirigkas dimasukkan/diletakkan di dalam rak penyimpanan.

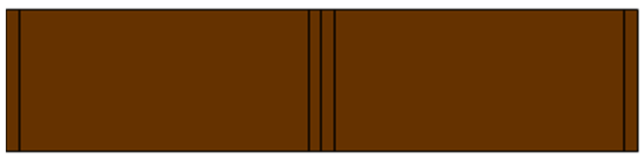

Gambar 18. Rak Penyimpanan 3 x 0,5meter

Berikut perhitungan fasilitas-fasilitas yang ada di dalam raw material setelah menerapkan racking system:

Luas rak biasa $=\mathrm{p} \mathrm{x} 1$

$$
=3 \mathrm{~m} \times 0,5 \mathrm{~m}
$$




$$
=1,5 \text { meter } 2
$$

Luas keseluruhan rak pada layout raw material setelah perbaikan yaitu $=(1,5$ meter $2 \mathrm{x}$ 6 rak $)=9$ meter2. Sehingga utilitas untuk rak penyimpanan itu sendiri sebesar $=9$ meter 2 .

Untuk rak khusus hose memiliki luas yang sama dengan rak penyimpanan gambar 4.19 Tetapi memiliki tinggi yang berbeda. Rak Hose tersebut memiliki spesifikasi sebagai berikut:

Panjang $=300 \mathrm{~cm}$

Lebar $=50 \mathrm{~cm}$

Tinggi $=320 \mathrm{~cm}$

Rak tersebut memiliki 4 sekat dalam bentuk tingkatan.Per sekat memiliki panjang sekitar $80 \mathrm{~cm}$.

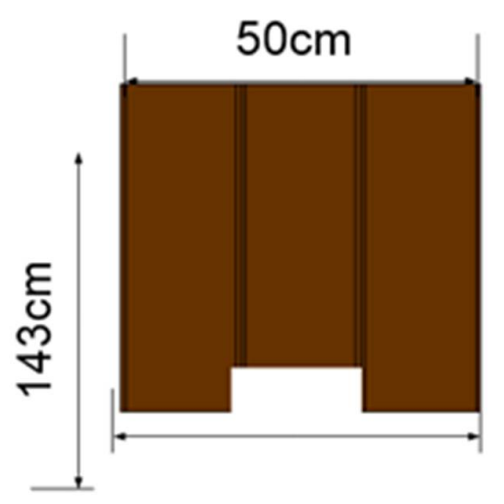

Gambar 19. Rak Untuk Material Kecil

Luas rak untuk material kecil $=\mathrm{p} \times 1$

$=1,43 \mathrm{~m} \times 0,5 \mathrm{~m}$

$=0,715$ meter 2

Luas rak pada gambar 4.20 Yaitu sebesar 0,715 meter2. Terdapat 3 rak penyimpanan sehingga utilitas untuk rak penyimpanan tersebut adalah $(0,715$ meter $2 \times 3$ buah $)=2,145$ meter 2 . Rak pada gambar 4.20 memiliki spesifikasi sebagai berikut:

$\begin{array}{ll}\text { Panjang } & =143 \mathrm{~cm} \\ \text { Tinggi } & =254 \mathrm{~cm} \\ \text { Tebal } & =50 \mathrm{~cm}\end{array}$

Memiliki sekitar 50 rak-rak kecil yang dignakan untuk menyimpan material-material yang memiliki ukuran kecil. Tiap rak kecil tersebut memiliki ukuran panjang $=25 \mathrm{~cm}$, tinggi $=20 \mathrm{~cm}$ dan tebal $50 \mathrm{~cm}$. Lemari tersebut dapat dibongkar pasang pada kotak-kotak penyimpanan barangnya.

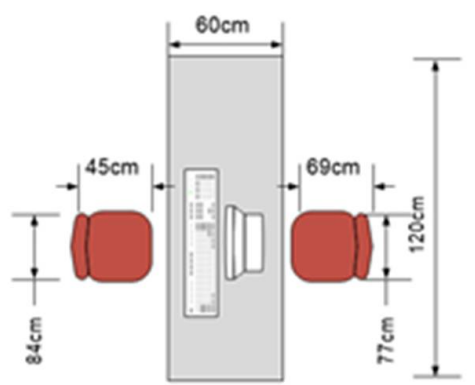

Gambar. 20 Meja Kerja Admin

Luas meja kerja admin $=\mathrm{p} \times 1$

$=0,6 \mathrm{~m} \times 1,2 \mathrm{~m}$

$=0,72$ meter 2

Luas tempat duduk admin $=\mathrm{p} \times 1$

$=0,84 \mathrm{~m} \times 0,45 \mathrm{~m}$

$=0,378$ meter 2

Luas tempat duduk supplier $=\mathrm{p} \times 1$

$=0,77 \mathrm{~m} \mathrm{x} 0,69 \mathrm{~m}$

$=0,53$ meter 2

Luas meja kerja admin yang terletak tepat di depan pintu masuk receiving area sebesar 0,72 meter2. Kemudian untuk luas tempat duduknya sebesar $=(0,378$ meter $2+0,53$ meter 2$)=0,908$ meter2. sehingga utilitas / penggunaan ruangan pada meja dan kursi sebesar $=0,72$ meter $2+$ 0,908 meter $2=1,628$ meter 2

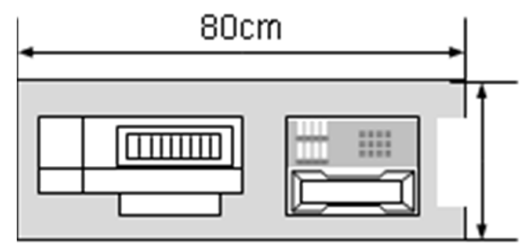

Gambar 21 Meja Printer danTelepon

Luas meja printer $=\mathrm{pxl}$

$$
\begin{aligned}
& =0,8 \mathrm{~m} \times 0,35 \mathrm{~m} \\
& =0,28 \mathrm{~meter} 2
\end{aligned}
$$

Luas meja printer yang terletak disamping meja kerja admin sebesar 0,28 meter2. Sehingga utilitas/penggunaan ruangan pada meja printer sebesar $=0,28$ meter 2

$$
\begin{aligned}
\text { Luas rak dokumen } & =\mathrm{p} \times \mathrm{l} \\
& =1,2 \mathrm{~m} \times 0,4 \mathrm{~m} \\
& =0,48 \text { meter } 2
\end{aligned}
$$

Rak dokumen pada gudang sebelumnya menempel pada dinding tepat diatas meja printer, kemudian setelah perbaikan layout rak dokumen yang diusulkan yaitu rak dokume yang duduk 
dengan luas rak sebesar 0,48 meter2. Rak buku pada gambar 4.24 Memiliki spesifikasi sebagai berikut:

Panjang $=120 \mathrm{~cm}$

Lebar $=50 \mathrm{~cm}$

Tinggi $=80 \mathrm{~cm}$

Untuk kain majun dan material dengan tempat berbentuk dirigen memiliki space tersendiri Untuk penyimpanan yaitu sebesar 1,5 meter $^{2}$.Setelah dilakukan perbaikan layout,maka perhitungan utilitas raw material dapat dijabarkan sebagai berikut:

Luas area keseluruhan $=640 \mathrm{~m}^{2}$

Luas area yang digunakan $=($ luas rak biasa+ luas rak untuk part - part kecil + luas meja kantor dan printer + luas material - material yang diletakkan di lantai + luas untuk kain majun,dll $)=9 \mathrm{~m}^{2}+145 \mathrm{~m}^{2}+408 \mathrm{~m}^{2}+0,48$ $+1,5 \mathrm{~m}^{2}=563,98 \mathrm{~m}^{2}$

Utilitas Ruang $=\mathrm{x} 100 \%$

$$
=37,11 \%
$$

Setelah dilakukan perbaikan layout, utilitas penggunaan raw material berkurang menjadi $37,11 \%$. Dengan utilitas pemakaian tersebut transportation time pada saat membawa material dari satu tempat ke tempat yang lain menjadi lancar dan operator/admin leluasa bergerak.

Salah satu waste yang terjadi pada raw material yaitu searching time yang lama pada saat pencarian material. Sebenarnya sudah terdapat sistem pelabelan pada material yang ada di gudang, tetapi tidak semuanya material diberi label dan kadang penempatan material tidak sesuai dengan label yang sudah tertulis sehingga pada saat mencari menjadi membingungkan. Terlebih lagi untuk material spesial untuk material pipe fitting yang jarak di stok oleh gudang.

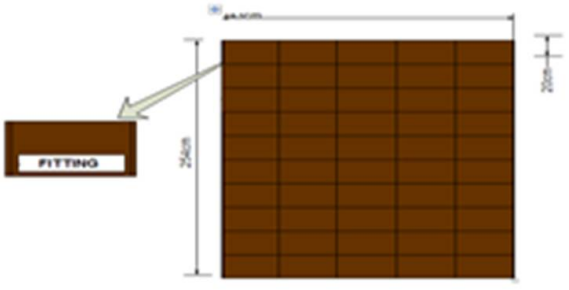

Gambar 22. Contoh Pengkodean/ Pelabelan

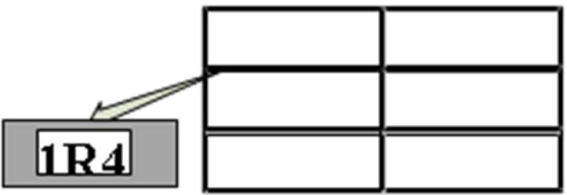

Gambar 23. Contoh Pengkodean/Pelabelan

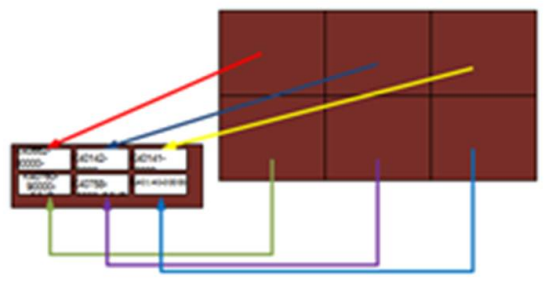

Gambar 24. Contoh Usulan Palet untuk Item 1 Nama untuk satu nama part.

Dalam penataan material untuk kedepannya lebih tertata lagi dan disesuaikan dengan jenis dan ukurannya. Hal ini akan mempermudah dalam pencarian dan mempersingkat waktu pencarian. Jika keseluruhan usulan perbaikan dapat diterapkan maka gudang PT. Nichirin Indonesia menerapkan $5 S+$ Safety dalam keseluruhan aktivitas yang ada di gudang.

\section{KESIMPULAN}

Aktivitas-aktivitas yang terjadi pada storeroom PT.Nichirin Indonesia diantaranya pengiriman barang dari supplier dan issue component.

Dapat dilihat dari value stream mapping dan diagram fishbone masing-masing aktivitas bahwa macam-macam pemborosan yang terjadi diantaranya:

- Waiting time pada aktivitas pengiriman barang dari supplier

- Transportation time pada kegiatan membawa barang dari luar menuju ke area receiving.

- Waiting time karena material harus menunggu ditata oleh admin/operator yang bekerja.

- Transportation time pada saat melakukan penataan barang ke rak

- Searching time pada kegiatan mencarikan material untuk kebutuhan produksi.

Usulan perbaikan yang yang diberikan kepada gudang PT. Nichirin Indonesia untuk mengurangi pemborosan yang terjadi diantaranya:

- Menambahkan material handling berupa trolley barang dan tangga untuk mempersingkat transportation time.

- Melakukan perubahan layout gudang. 
- Memberikan pelabelan/pengkodean pada setiap area rak material.

Gudang PT. Nichirin Indonesia merupakan sebuah gudang material dimana tempat tersebut tempat penyimpanan bahan baku,maka perlu warehouse management harus benar-benar diterapkan dalam gudang agar kegiatan dalam gudang berjalan dengan lancar. Perlu adanya peningkatan evaluasi secara periodik mengenai rencana produksi agar produksi diperiode berikutnya dapat berjalan dengan lebih baik.

Menerapkan $5 S+$ Safety dalam gudang sangat penting untuk gudang. Dengan menerapkan $5 S+$ Safety tersebut maka dapat meminimalisir pemborosan-pemborosan apa saja yang terjadi.

\section{REFERENSI}

[1] Jeffrey K. Liker, (2003). The Toyota Wey : 14 Management Principles From the World's Greatest Manufacturing. McGraw Hill

[2] Alex, S., Lokesh, C. A., Ravikumar, N., (2010). Space utilization improvement in CNC machining unit through lean layout. Sastech Journal, 9(2).

[3] Anvar, M. M., \& Irannejad, P. P., (2010). Value stream mapping in chemical processes: A case study in Akzonobel Surface Chemistry, Stenungsud, Sweden. Proceedings of the Lean Advancement Initiative, Daytona Beach, Florida.

[4] Bhat, R., \& Shivakumar, S., (2011). Improving the productivity using value stream mapping and kanban approach. International Journal of Scientific \& Engineering Research, 2(8), 2229-5518.

[5] Bonaccorsi, A., Carmignani, G., Zammori, F., (2011). Service Value Stream Management (SVSM) : Developing Lean Thingking in the Service Industry. Journal Of Service and Management, (4), 428-439.

[6] Chen, L., \& Meng, B., (2010). The application of value stream mapping based lean production system. International Journal of Business and Management, 5(6).

[7] Dharmapriya, U. S. S., \& Kulatunga, K. A., (2011). New strategy for warehuse optimization - Lean warehousing. The Proceedings of the International Confrence on Industrial engineering and Operation Management, Kuala Lumpur, Malaysia. 